\title{
Non-Medical Prescribing
}

\author{
Maj J D C Bennett \\ BSc, FRCS, DCH, RAMC \\ Lecturer
}

University Department Otolaryngology, Manchester Royal Infirmary, Manchester M13 9WL

\author{
Capt P Haynes \\ MRCP, RAMC \\ Specialist in Medicine
}

Mil Wing, Musgrave Park Hospital, BFPO 801

\begin{abstract}
SUMMARY: Non-medical prescribing is increasingly being seen as a cost effective option by both the government and paramedical professional bodies. The use of potentially dangerous preparations in a wide range of clinical settings is not without danger, as illustrated by this case of facial palsy associated with the use of a proprietary brand of wax softener in an ear with a perforated ear drum.
\end{abstract}

\section{Introduction}

The Health Department Advisory Group on nurse prescribing produced a report last year recommending limited prescribing rights (1). In conjunction with this the Department of Health has proposed an increased advisory role for pharmacists (2). Whilst welcoming any development which improves patient care and at the same time help to contain the ever-escalating cost of providing such care, the caution implied by Health Minister Virginia Bottomley:

"We fully support the general principle of nurse prescribing. But before making the final decisions we must weigh up carefully the implications - for costs, for working arrangements and for patients" (3)

seems appropriate. A case is described where a temporary facial palsy may have been associated with inappropriate prescribing by non-medical personnel.

\section{Case Report}

A healthy 21 year-old soldier developed a right-sided earache which had not abated after 24 hours. He had had no previous problems with his ears and complained of no symptoms other than pain. He was given some $\mathrm{Waxso}^{\mathrm{R}}$ (R. Waxsol: Docusate Sodium BP $0.5 \% \mathrm{w} / \mathrm{v}$ in a water miscible base, Norzine UK) ear drops to instil into the ear. On doing so he was immediately aware of the taste of the drops and the right side of his tongue became numb. Within a few hours the right side of his face - became paralysed. He was admitted to hospital where it was apparent that he had a profound lower motor neurone palsy of the right facial nerve. The right external auditory meatus was inflamed and a perforation of the anterior upper quadrant of the tympanic membrane was seen. Lacrimation was not affected, implying that the lesion lay distal to the site of origin of the greater petrosal nerve - i.e. beyond the geniculate ganglion. Tests for the localisation of the site of the lesion are, however, notoriously unreliable (4). Within a month the perforation had closed spontaneously and the facial palsy was lessening with the eyelid being able to be almost closed but with little movement at the angle of the mouth. By six months he had made an almost complete recovery, being left with only a slight facial asymmetry.

\section{Discussion}

It is not possible to say with any degree of certainty whether the facial palsy was a result of the instillation of a wax softener through a perforation of the ear drum or whether it was a true Bell's palsy. Pain does occur in nearly all cases of Bell's palsy in the 24 hours before onset (5). The perforation may have been a consequence of an acute otitis media or have been long-standing. The agent used caused a nasty reaction in the ear causing it to become red and swollen, which can often be found with proprietary keratolytic agents, thus complicating the matter further. The wisdom of applying a wax softener in such a case must be questioned. The one used, WaxsolR $^{R}$, has as its active ingredient docusate sodium. This is an ionic sufactant which acts by allowing water to penetrate hydrophobic linkages - in this capacity it is also used as a laxative. The facial nerve canal within the middle ear has a smooth rounded lateral surface that is occasionally deficient (6). The incidence of this has been estimated as high as $5 \%$ (7). The surfactant action of the chemical on an exposed facial nerve might well have caused the paralysis. Such a course could not have been foreseen and one must bear in mind that a wide range of products on the "P classification" list are available for direct purchase across the counter in pharmacies. However, as has been becoming apparent recently, the medical profession is seeing an erosion of its traditional role (8), with nurses (1) and other professions allied to medicine seeking a role in prescribing. The incidence of patients receiving medications without the knowledge or agreement of their doctor is likely to increase. 


\section{Conclusion}

The transfer of some of the workload from the medical profession to professions supplementary to medicine may not necessarily lighten the medical workload by the same amount. The problem of clinical responsibility has not been fully addressed and the caution shown by the Minister of Health for such a move is probably well founded.

\section{Acknowledgment}

We are grateful to Jane Burgneay MSc, Staff Audiologist, Institute of Sound \& Vibration Research, University of Southampton for help and advice.

\section{REFERENCES}

1. Peachey M. Nurses Demand Prescribing Rights. BMA News Review 1991; 8: 8.

2. Which? Way To Health Report. The Daily Telegraph 10 Dec 1991.

3. Bottomley V. quoted in News. Nursing Standard 1991; 5: 9 .

4. Fisch U. Prognostic value of electrical tests in acute $\overrightarrow{\vec{c}}$ facial paralysis. Am J Otol 1984; 5: 494-498.

5. PATtEN J P. Neuroanatomy and applied neurophysiology for the otolaryngologist. In Scott Brown's Otolaryngology. Kerr A G (ed). London: Butterworth 1987 Vol 1, p397.

6. WRIGHT A. Anatomy and ultrastructure of the human ear. In Scott Brown's Otolaryngology. Kerr A G (ed). London: Butterworth 1987 p18.

7. Shambaugh G E. Surgery of the Ear. London: W B Saunders $1967 \mathrm{p} 57$.

8. FERGUSON J. Letter. Br Med J 1991; 302: 787. 